\title{
The relative effects of nonreward and response thwarting on the frustration effect
}

VINCENT DI LOLLO, R. C. DAVIDSON, G. R. HAMMOND AND R. J. DONOVAN, UNIVERSITY OF WESTERN AUSTRALIA

Studies of the frustration effect (FE) have confounded the facilitative effect of frustrative nonreward on $R_{2}$ performance with the possible energizing effect of response blocking in $G_{1}$. To separate these two effects two groups of 11 rats were run in a double-runway to continuous reinforcement in $G_{1}$ and $G_{2}$, and were then shifted to partial reinforcement in $G_{1}$. One group was confined in $G_{1}$ on nonrewarded trials; the other group was never confined. Facilitation of $R_{2}$ performance was affected jointly by frustrative nonreward and response blocking in $G_{l}$.

The term "frustration effect" (FE) refers to an increment in vigor of the responses which occur soon after a frustrating event. It has been reliably demonstrated in a double runway apparatus consisting of start box (SB), first runway $\left(R_{1}\right)$, first goal box $\left(G_{1}\right)$, second runway $\left(R_{2}\right)$, and second goal box $\left(G_{2}\right)$. Typically (e.g., Amsel, 1958 ), Ss receive continuous reinforcement in $\mathrm{G}_{2}$ but are given nonrewarded trials interspersed with, or following, rewarded trials in $G_{1}$. The increased vigor of responding in $R_{2}$ on nonrewarded trials has been attributed (Amsel, 1958) to an increment in drive level contributed by frustration resulting from nonreward in $G_{1}$.

Results similar to those described in the foregoing have been observed in several studies (e.g., Holder, Marx, Holder, \& Collier, 1957) in which the running response in a single runway was blocked for a few seconds before the $S$ reached the goal box. The increment in vigor of the postdelay performance has been attributed (Brown \& Farber, 1951) to frustration arising from the thwarting of the ongoing instrumental approach response.

In FE experiments, on rewarded trials Ss are released from $G_{1}$ as soon as the reward is consumed; on nonrewarded trials, however, they are confined in $G_{1}$ for a few seconds and then released. Clearly, the effects of thwarting and nonreward on performance in $R_{2}$ are confounded: The increased vigor of responding in $\mathbf{R}_{2}$ could be explicable in terms of thwarting, nonreward, or both these factors.

That nonreward per se has energizing properties for the responses that follow may be surmised from a study by Wagner (1959) who found that a control group never rewarded in $G_{1}$ ran slower in $R_{2}$ than an experimental group following nonreward in $G_{1}$. The two groups presumably experienced similar thwarting on the relevant trials, thus allowing a demonstration of the energizing effect of frustrative nonreward. These results, however, have been queried in a study comparable to Wagner's (McHose, 1963) where no significant differences were found in $\mathbf{R}_{\mathbf{2}}$ performance between the two relevant groups.

What is needed is an answer to the question: Does frustrative nonreward have energizing properties independently of thwarting? And, if it does, what are the relative contributions of thwarting and nonreward on the observed increment in the vigor of responding in $R_{2}$ following frustrative nonreward in $G_{1}$ ?

In the study reported here, two groups were run to continuous reward in both $G_{1}$ and $G_{2}$ and were then shifted to partial reinforcement in $G_{1}$. For one group, the doors in $G_{1}$ were always open, thus avoiding any possibility of response blocking. The relative contributions of thwarting and nonreward could then be assessed by comparing the performance of the two groups in $R_{2}$ following nonreward in $G_{1}$.

\section{Method}

Subjects. The Ss were 22 male albino rats from the colony maintained at the University of Western Australia. They were housed four to a cage and were approximately 120 days old at the beginning of the experiment.

Apparatus. The Ss were run in a double runway made from $1 / 2$ in. plywood. The internal dimensions were: overall length, $13 \mathrm{ft}$; height, 4 in.; width, 2-5/8 in. The overall length was made up of start box (SB) 12 in., first runway $\left(R_{1}\right) 5 \mathrm{ft}$, first goal box $\left(G_{1}\right) 12$ in., second runway $\left(R_{2}\right) 5 \mathrm{ft}$, and second goal box $\left(G_{2}\right) 12$ in. Clear Perspex doors, which opened downward, controlled access to the runways from $S B$ and $G_{1}$. Similar retrace doors closed automatically in both $G_{1}$ and $G_{2}$ when the $S$ broke a photobeam $1 / 2 \mathrm{in}$, above the food cups. These consisted of a square metal dish $3 / 4$ in. wide $x 1 / 4$ in. deep attached to a metal stand 1-1/8 in. off the floor so that the approaching animals could not see the food. One food cup was placed in the far lefthand corner of $G_{1}$ and $G_{2}$. Photocells and lamps with infrared filters were installed in $R_{2} 11$ in. past $G_{1}$ and 1 in. before $G_{2}$. The interruption of these light beams caused signals to be placed on a magnetic sound tape moving at constant speed. Running times were recovered, with a resolution of $20 \mathrm{msec}$, when the tapes were played through an interface into a DEC PDP-6 computer.

Procedure. Ten days before the beginning of training Ss were placed on a $23 \mathrm{~h}$ food deprivation schedule with water available at all times. For the last five days, Ss were handled together for $30 \mathrm{~min}$ daily on a large metal tray covered with sawdust. After handling, food was available for $1 \mathrm{~h}$. Ss were assigned at random to two groups of $11 \mathrm{Ss}$ each. During Acquisition, all Ss were continuously reinforced with four $20 \mathrm{mg}$ Noyes pellets in both $G_{1}$ and $G_{2}$. The $S s$ in Group NB (not blocked) were never confined in $G_{1}$, both start and retrace doors in $G_{1}$ being always open; the $S s$ in Group $B$ (blocked) were confined in $G_{1}$ until they had eaten and then faced the start door. One trial was run on each of the first 


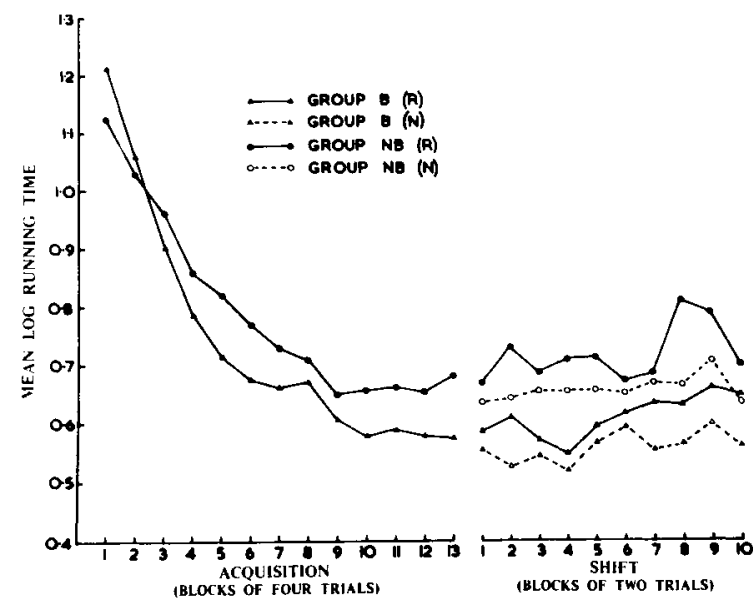

Fig. 1. Mean log running time ( $f t / \mathrm{sec}$ ) in $R_{\mathbf{2}}$. See text for further description.

two days of Acquisition, two on the third day, then four trials a day for the next 12 days, making a total of 52 Acquisition trials. The Ss were run in rotation with an intertrial interval of approximately $15 \mathrm{~min}$; water was always available in the holding boxes. On Trial 53 all Ss were shifted to $50 \%$ reinforcement in $G_{1}$ for 40 further trials at four trials per day. The sequence of rewards was a recycling of the following schedule: RNRN, NRNR, NRRN, RNNR, NNRR, RRNN, where R represents rewarded trials and $N$ nonrewarded trials in $\mathrm{G}_{1}$. On rewarded trials the treatment for each group was the same as during Acquisition. On nonrewarded trials, Ss from Group B were confined in $G_{1}$ for $5 \mathrm{sec}$ and then released; the Ss in Group NB were never confined. Continuous reinforcement was maintained in $\mathrm{G}_{2}$ throughout the experiment. One $S$ in Group NB died, thus leaving $11 \mathrm{Ss}$ in Group B and 10 in Group NB.

\section{Results and Discussion}

The running time in $\mathbf{R}_{2}$ of each $S$ on each trial was transformed logarithmically and then averaged for each group over blocks of trials to give the measure of performance shown in Fig. 1. Blocks of four trials and two trials were plotted for Acquisition and Shift, respectively. During Shift, the mean of the two daily trials on which Ss were rewarded in $G_{1}(R)$ and the two dally trials on which they received no reward $(N)$ were plotted separately.

During Acquisition the effects of Trials was significant $(F=99.10, \mathrm{df}=12 / 228, \mathrm{p}<.001)$, as was the Groups by Trials interaction $(F=4.65, \mathrm{df}=12 / 228, \mathrm{p}<.001)$. No other effects reached significance.

The divergence of the performance curves of the two groups during Acquisition may be the result of a short period of confinement which the Ss in Group B experienced in $G_{1}$ between the time they finished eating and the time they were actually released into $R_{2}$. This interpretation is consonant with the observation that the effect developed over trials and is in accordance with the results reported by Holder et al (1957). All FE experiments possibly have contained this effect, but it went undetected since the nonblocked controls were missing.

During Shift the significant effects were those of
Trials $(F=2.51, \mathrm{df}=9 / 171, \mathrm{p}<.01)$, Groups $(F=5.84$, $\mathrm{df}=1 / 19, \mathrm{p}<.05)$, and Reward vs Nonreward in $\mathrm{G}_{1}$ $(F=40.93$, df $=1 / 19, p<.001)$. No other effects, notably the interaction between Groups and reward conditions in $G_{1}(F=0.64)$ were significant.

The energizing effects of frustrative nonreward on performance in $\mathbf{R}_{\mathbf{2}}$ was obtained in both groups; its magnitude, however, was not related to response blocking in $G_{1}$. Given that the superior performance of Group B over Group NB on rewarded trials stemmed from response blocking as discussed in the foregoing, nonreward appears to act in conjunction with thwarting in energizing the $R_{2}$ performance of Group $B$. On this basis, the difference in the postshift performance of Groups $B(R)$ and $N B(R)$ represents the effect of response thwarting, and the difference between Groups $B(R)$ and $\mathrm{NB}(\mathrm{N})$ represents the joint effects of thwarting and nonreward. Results entirely consistent with this interpretation have recently been reported by Blanchard (1967) who obtained faster running speed under conditions of frustrative nonreward plus response blocking than under frustrative nonreward alone.

It is clear that in all the earlier FE experiments the effect of frustrative nonreward on performance in $\mathbf{R}_{2}$ was confounded with other sources of response facilitation-notably, response thwarting. The confounding did not, however, lead to serious misinterpretation of the data since frustrative nonreward per se appears to have an effect of approximately the same magnitude whether or not there is also an effect due to response blocking in $G_{1}$. If, however, the effect of frustrative nonreward is to be studied independently of other sources of response facilitation, the experiment must be carried out without doors in $\mathrm{G}_{1}$.

Recent studies (Hamm, 1967) have shown that differences in postshift performance are due to a decrement in speed in $R_{2}$ following $R$ trials as well as to an increment in speed following $\mathrm{N}$ trials. It is not possible to determine from the present study whether either or both of these phenomena are affected by response thwarting in $\mathbf{G}_{1}$.

References

AMSEL, A. The role of frustrative nonreward in noncontinuous reward situations. Psychol Bull, 1958, 55, 102-109.

BLANCHARD, R. J. Effect of response blocking on the acquisition of instrumentally rewarded responses. J. exp. Psychol., 1967, 73, 483-484.

BROWN, J. S., \& FARBER, I. E. Emotions conceptualized as intervening variables - with suggestions towards a theory of frustration. Psychol. Bull., 1951, 48, 465-495.

HAMM, H. D. Perseveration and summation of the frustration effect. J. exp. Psychol., 1967, 73, 196-203.

HOLDER, W. B., MARX, M. H., HOLDER, E. E., \& COLLIER, G. Response strength as a function of reward in a runway. $J$. exp. Psychol., 1957, 53, 316-323.

McHOSE, J. H. Effects of continued nonreinforcement on the frustration effect. J. exp. Psychol, 1963, 65, 444-450.

WAGNER, A. R. The role of reinforcement and nonreinforcement in an "Apparent frustration effect".J. exp. Psychol., 1959, 57, 130-136. Note

1. This research was supported by the Air Force Office of Scientific Research, Office of Aerospace Research, United States Air Force, under AFOSR Grant Nr AF-AFOSR-968-65 to the first author. 